\title{
Performing PowerPoint lectures: examining the extent of slide-text integration into
}

\section{lecturers' spoken expositions}

Madeline J. Hallewell ${ }^{1}$, Learning Sciences Research Institute, University of Nottingham, Nottingham, NG8 1BB. ORCID ID: orcid.org/0000-0002-2710-2176 @ MaddyJHallewell

Charles Crook, Learning Sciences Research Institute, University of Nottingham, Nottingham, NG8 1BB. ORCID ID: orcid.org/0000-0002-2793-9793 @ charlescrook

Citation: Madeline J. Hallewell \& Charles Crook (2019): Performing PowerPoint lectures: examining the extent of slide-text integration into lecturers' spoken expositions, Journal of Further and Higher Education, DOI: 10.1080/0309877X.2019.1579895

This is an Accepted Manuscript of an article published by Taylor \& Francis in The Journal of Further and Higher Education on 11/03/18, available online: https://www.tandfonline.com/doi/full/10.1080/0309877X.2019.1579895

${ }^{1}$ Corresponding author 


\begin{abstract}
The PowerPoint assisted lecture (slide-lecture) is a common lecturing approach in Higher Education, in spite of much criticism of its use. Its popularity is facilitated by its affordances for multimodal instructional design, e.g. text with images and speech. Little is known about the integration of different semiotic modalities within the instructional communication practices of slide-lectures, nor the learning conditions that they create. Given that text bulletpoints are ubiquitous in slide-lectures, and may impose linearity into instructional communications (Kinchin et al., 2008), this study explores the extent to which lecturing speech is systematically coordinated with slide-text.
\end{abstract}

Eleven slide-lectures given in psychology departments across the UK were recorded and transcribed. Patterns of semantic matches between speech and slide-text were analysed to produce similarity scores for each lecturer. Lectures were scored using an integration scoring system of $0-1$, with 1 indicating a perfect match of speech and slide-text. There was significant departure from a systematic voicing of the slide text (i.e. reading off the slides).

Two characteristic speech-slide relationship styles were identified. The 'referent' style is one in which the slide is an object of reference for the lecturer to comment on, and the 'scaffolding' style is one in which the slide text is blended into the spoken narrative. Consequences of the lecturer's coordination with presentational slides are discussed in terms of the learning environment it might produce. It is suggested that whichever relationship a lecturer has with their slide-text, students might benefit from the integration being consistent.

\title{
Key Words:
}

Slide-lectures, Lecturer-slide orchestration, mixed-methods, PowerPoint pedagogy, multimodal communication 


\section{Introduction}

The slide-lecture is defined as a lecture, or section of a lecture, in which a large electronic display shows a sequence of discrete visual screens (text, multimedia, or a combination of both) whilst the lecturer speaks. Importantly, owing to the affordances of slide software (e.g. PowerPoint, Prezi, Keynote), slide-lectures have the potential to be multimodal performances in which voice is coordinated with visual information. Although there are many other activities that could be carried out within a lecture, and lectures certainly do not all follow the slide-lecture format, under discussion here are the lectures (or sections of lectures) in which slides appear on the screen to support the lecturer's presentation.

The efficiency with which multimedia encounters in general can be processed are widely discussed (e.g. Jewitt, 2009; Pozzer-Ardenghi, 2007; Ainsworth, 2006; Smith- Shank, 2010). In multimedia/multimodal learning and instruction, the incorporation of information presented in different modalities is generally helpful - provided there is a clear instructional purpose for each modality and the information conveyed by each is integrated for efficient cognitive processing (e.g. Mayer, 2001). However, little of the literature associated with multimedia/multimodal learning and instruction relates specifically to the live slide-lecture as a particular form of such pedagogy. The practices of integrating its modes of spoken and visualised communication are poorly understood.

A live lecture can be a semiotically-rich occasion but its most prominent communicative modes are the lecturer's speech and the visual representations displayed on screens. Hallewell and Lackovic (2017) have discussed the semiotic potential of photographs in lecture slides, concluding that it is important that speech and photographic modalities are integrated and photographs are interrogated to lead to a more nuanced and personally meaningful understanding of lecture content. Yet in their study, photograph usage was very 
low compared to the use of text on slides. The present study extends this work to address practices of managing visible text within slides.

Of the many representational forms available (images, videos, animations etc.), the most common modality to appear in slideshows is text (Gabriel, 2008). There is little established protocol regarding how slide-text functions as part of the slide-lecture performance, yet there is much criticism of the 'typical' way in which such 'speaking-aboutthe-slide' is achieved. For instance, the PowerPoint 'paradigm' of teaching results in the lecturer using their slides as a reduced script, giving 'boring' presentations (Adams, 2006; Maxwell, 2007; Nowak et al., 2016; Knight, 2015) of information that may already have been encountered via lecture material posted on a course Virtual Learning Environment (Gourlay, 2012). Seemingly, slides are understood as a text-based outline of the lecture performance, dictating the topics which the lecturer will address and which students should study further. The subsequent restriction that slides place on lecture progression is blamed for student disengagement, which may result in skipping classes, daydreaming, playing with phones etc. (Mann and Robinson, 2009). Moreover, this 'lecture-outline' model of slide-lectures might converge on the limiting case of the lecturer who reads slide-text verbatim, a practice which can surely produce 'dull' lectures (Young, 2004; Knight, 2015) and which condemns the lecturer to a role of spokesperson for the slide.

There is clearly a tension within lecturing practice; slide-lectures are ubiquitous and are likely to remain so for some time, yet there is a common understanding that their typical performance might negatively influence lecture-based communication. There is a need for ways of expressing how the lecturer's speech and the slide-text are integrated in order to understand how slides might enhance rather than disturb lecture-based communication. 
The common critique of slide-lectures paints a picture of lecturers systematically reading bulletpoint after bulletpoint, perhaps expanding some points along the way. Indeed, the very nature of slidewares restricts the author to a linear, sequential progression of the lecture material (Kinchin et al., 2008).Yet there are few existing frameworks that help us evaluate the extent to which the lecturer's speech identifies and addresses slide text in a particular pattern. The identification of the specific item (e.g. bulletpoint) in question can be achieved with pointers, animation and other non-speech forms of reference. These methods can give an unmistakable cue about which slide item is being spoken about, and therefore which part of the text to attend to at a particular time. However, the usage of these is by no means consistent and reliable, and may depend upon the lecturer's physical position in relation to the slide display. Bucher and Niemann's (2012) eye tracking studies reveal the importance of visual and verbal referential actions (both physically by pointing or linguistically through speech): both can direct the audience's attention to relevant information. Speech forms a more significant component of lectures than physical pointing practices, and as such this paper considers the extent to which this integration is performed through the lecturer's speech only.

Schnettler's (2006) characterisation of presenters as either 'orators' or 'performers' comes close to describing the integration of slide-text with speech in patterned terms; presenters either simply verbalise the slide-text or they approach text and speech as material to be inter-weaved to a more considered performance. Yet description about how this is managed in lectures is lacking. Despite much negative commentary about typical synchronisation practices, there is little evidence relating to the extent that systematic synchronisation of speech and slide is achieved during lecturing. We shall focus on the interplay between speech and slide-text during slide-lectures, in order to illustrate the performance of slide-lecture mediation through examining how far lecturers systematically 
mirror their slide-text with their speech. The research questions guiding this study are as follows: to what extent do lecturers integrate slide-text with their speech in a systematic manner; and are there characteristic ways in which this integration is achieved?

\section{Materials and Methods}

Data collection took the form of a naturalistic video observation of 12 undergraduate psychology lectures given across the UK during the academic year 2009/10. In a discipline which deals with a mix of methods and representations, a single, iconic and introductory topic was sought for observation. Attachment Theory in developmental psychology was selected as it is typically covered to a well-established expository pattern. Ethical approval was confirmed prior to carrying out data collection.

Rather than focus on a single institution - which may impose idiosyncratic lecturing practices across its programmes - an opportunity sample was gathered from a mix of UK universities. Lecturers in eighteen psychology departments were approached, and of those, 12 fit the criteria of teaching first year Attachment Theory and were willing to participate.

Participants were given the option of either making a recording of their Attachment Theory lecture using a small, portable video recorder sent to them in the post, or allowing a researcher to visit and record the lecture using the same device. The video recorder was sent to 11 participants in advance of their lecture, along with instructions. The instructions requested that the recorder was to be set up in a position which captured the main display screen or focal point in the lecture theatre, along with the lecturer's speech, but not necessarily including the lecturer themselves (unless unavoidable). It was also required that students' faces were not visible on the recording, and that students were made aware of the recording prior to the start of the lecture. In one instance a researcher made the recording by being positioned at the front of the lecture theatre with the recorder pointed at the display 
screen. In total, 12 lecture videos were collected from 12 different lecturers, each comprising a slide presentation accompanied by the lecturer's speech.

All lectures were transcribed verbatim, with the exception of one which was excluded from the analysis owing to the exceptionally poor quality of the recording. During the transcribing process, slide transitions were used to split the speech into sections, such that each slide was displayed side-by-side with the accompanying speech. Where a lecturer changed slides mid-sentence, that sentence was divided between the slides at the point of transition. The slide-text was also transcribed for ease of analysis.

It was noted that slides included many other types of representation: graphs; diagrams; photographs; images; numbers; formulae; videos; web links; and dynamic diagrams. Of the 2095 distinct slide-elements found on 413 slides, text-elements (in the form of bulletpoints, structural headings, and quotes) made up $91.57 \%$ of slide-elements (1923 of 2095 total slide-elements). The next most prevalent representation was photographs (appearing 68 times or as $3.24 \%$ of total slide-elements), which are dealt with separately in Hallewell and Lackovic (2017). Table 1 describes the characteristics of the lectures.

Table 1: Characteristics of the lectures.

\begin{tabular}{|l|l|l|l|l|}
\hline $\begin{array}{l}\text { Lecturer } \\
\text { pseudonym }\end{array}$ & $\begin{array}{l}\text { Length of } \\
\text { Lecture } \\
\text { (hr:min:sec) }\end{array}$ & $\begin{array}{l}\text { No. of } \\
\text { Slides }\end{array}$ & $\begin{array}{l}\text { No. of single text- } \\
\text { elements in lecture (a } \\
\text { bulletpoint, a single } \\
\text { piece of structural } \\
\text { text/heading, a quote) }\end{array}$ & $\begin{array}{l}\text { \% of text-elements } \\
\text { used in relation to } \\
\text { other elements (e.g. } \\
\text { photographs, } \\
\text { diagrams, graphs) }\end{array}$ \\
\hline Wright & $00: 55: 10$ & 42 & 209 & 96.3 \\
\hline Moss & $00: 35: 03$ & 24 & 115 & 84.5 \\
\hline Leaman & $00: 52: 29$ & 34 & 175 & 88.9 \\
\hline Vickers & $01: 22: 33$ & 43 & 292 & 97.1 \\
\hline Lake & $00: 51: 57$ & 21 & 83 & 93.3 \\
\hline Ealy & $00: 54: 59$ & 26 & 100 & 89.3 \\
\hline Jackson & $00: 39: 39$ & 22 & 52 & 72.2 \\
\hline Cooper & $00: 42: 33$ & 30 & 215 & 98.2 \\
\hline Kemp & $01: 04: 59$ & 70 & 289 & 97.0 \\
\hline Underwood & $01: 40: 54$ & 65 & 196 & 78.4 \\
\hline Horsley & $01: 13: 44$ & 36 & 197 & 96.6 \\
\hline
\end{tabular}




\begin{tabular}{|l|l|l|l|l|}
\hline Total: & - & 413 & 1923 & - \\
\hline Mean & - & 37.55 & 174.82 & - \\
\hline SD & - & 16.62 & $\mathbf{7 9 . 4 9}$ & - \\
\hline
\end{tabular}

To consider the integration of slide-text with speech, only the slides that contained these 1923 text-elements were selected for analysis. Thus 336 out of 413 slides were analysed.

\section{Results}

Each individual text-element was labelled alphabetically according to the position in which it appeared on the slide. It was assumed that slides are intended to be read from top-tobottom and left-to-right. For instance, Figure 1 below shows an example of such reading along with the coding of its four text-elements;

A John Bowlby 1907-1990

B Studied Psychology, pre-medical sciences. medicine \& trained as a psychoanalyst (UK in the $1930^{\text {th }}$ )

c Worked with delinquent and affectionless children and studied the effects of hospitalised and institutionalised care (Tavistock Clinic London)

D WHO report on the mental health of homeless children in post-war Europe 1951

Figure 1: Example of coding of the expected order of slide-text

Identification of the integration of slide-text with speech was carried out using a

Discourse Analysis (DA) framework (Coulthard, 2014) which compared the semantic content 
of the speech with the semantic content of the text. The identifiers of speech-text integration are described in Table 2. This table is an expansion of Knoblauch's (2008) 'secondary pointing procedures' (SPPs) in which speech points to text without the use of physical pointing methods. These identifiers were selected from the limited frameworks available for analysing the communicational practices of slide-lectures. Some identifiers were added to reflect the practices of lectures specifically, as Knoblauch's identifiers were developed from business presentations. It should be noted that although the observation of animation schemes would have been possible for some lecturers, the inconsistency of their use rendered them unreliable as a pointing procedure.

Table 2: Identifiers of integration of text with speech based on Knoblauch's (2008) SPPs

\begin{tabular}{|l|l|}
\hline $\begin{array}{l}\text { Secondary Pointing } \\
\text { Procedure }\end{array}$ & Definition \\
\hline $\begin{array}{l}\text { Recognition markers \& } \\
\text { paralleling whole sentences }\end{array}$ & $\begin{array}{l}\text { Spoken words that are also present in the slide-text } \\
\text { (Knoblauch, 2008: p. 87). For example reading entire } \\
\text { sentences from the slide, or simply speaking the } \\
\text { significant words present in the text. }\end{array}$ \\
\hline Itemizations & $\begin{array}{l}\text { Providing there is more than one element present on the } \\
\text { slide, the speech addresses the structure of the slide and } \\
\text { the pattern of the objects within. For instance, when } \\
\text { displaying a list, by saying 'first' the speaker points to } \\
\text { the first text-object and by saying 'then' they point to } \\
\text { the next. }\end{array}$ \\
\hline Direction \& Demonstratives & $\begin{array}{l}\text { The speech directly addresses the object such as 'this } \\
\text { notion', or 'these things'. }\end{array}$ \\
\hline $\begin{array}{l}\text { Reformulating the } \\
\text { text/'mangling' }\end{array}$ & $\begin{array}{l}\text { Although the concepts are the same in speech and text, } \\
\text { the speech can be so different in structure and } \\
\text { terminology to the point where they are two separate } \\
\text { entities which give the same semantic message. }\end{array}$ \\
\hline
\end{tabular}

Using these SPPs, the speech transcripts were scrutinised alongside the slide-text to establish where integration occurred. The speech that integrated the text-element(s) was alphabetically coded accordingly, such that the coding produced an 'expected' pattern (slide), and an 'observed' integration pattern (speech). Figure 2 below is an example of such coding: 


\begin{tabular}{|r|l|r|l|}
\hline $\begin{array}{l}\text { Expected } \\
\text { pattern }\end{array}$ & Slide-text & $\begin{array}{l}\text { Observed } \\
\text { pattern }\end{array}$ & Speech \\
\hline A & Theories of attachment & None & $\begin{array}{l}\text { What's more important is } \\
\text { that } \\
\text { consistently and appropriately to } \\
\text { their infants' bids for attention }\end{array}$ \\
C & $\begin{array}{l}\text { Mothers who often played with } \\
\text { their babies }\end{array}$ & B & $\begin{array}{l}\text { Cothers or fathers respond } \\
\text { appropriately to the infant's } \\
\text { needs, }\end{array}$ \\
D & $\begin{array}{l}\text { These mothers were closely } \\
\text { attached to their infants }\end{array}$ & D & $\begin{array}{l}\text { that they play with the } \\
\text { infants, when that happens, } \\
\text { these mothers become } \\
\text { closely attached to their } \\
\text { infants. }\end{array}$ \\
\hline
\end{tabular}

Figure 2: Example of coding of one slide and speech excerpt

Where a lecturer integrated two text-elements, for instance by saying 'these two points', the speech was coded with both associated letters alphabetically. Where the speech integrated more than two text-elements, for instance by saying 'this slide', it was considered integration of the whole slide and therefore was not coded.

Note that this analysis concerns only speech in which the slide-text was being addressed. Speech that develops on the slide-text, explains and expands on it (in which case the speech is related to the slide-text but is not immediately identifying the text to be attended to), housekeeping interactions ('can everybody hear me?') and tangential speech was disregarded. Although this kind of speech is relevant to the student's general topic understanding, what is important to this study is the extent to which the speech assists in the initial identification of relevant slide-text.

\section{Reliability of the SPPS}

The SPPs were given to a colleague who coded a randomly selected $10 \%$ of the slides and their associated speech for each lecturer. It was noted for each text-element whether both the researcher and this colleague believed the speech was integrated with the slide-text (scoring 1) or not integrated (scoring 0) with the speech for each coder. The specific SPP 
used was not noted. Substantial agreement was found using the Kappa statistic to determine consistency amongst coders: Kappa $=0.844(p<0.001)$. Thus, confidence was high that the process of judging integration was reliable.

\section{Expected versus observed pattern of integration}

The 'expected' and 'observed' patterns represent the integration of the text-element on each slide for comparison. For example, the expected pattern of the slide in Figure 2 above would be A, B, C, D, but the observed pattern was B, C, D.

\begin{tabular}{|c|c|c|c|}
\hline Jackson & & Leaman & \\
\hline $\begin{array}{l}\text { Expected pattern } \\
\text { (slide) }\end{array}$ & $\begin{array}{l}\text { Observed pattern } \\
\text { (speech) }\end{array}$ & $\begin{array}{l}\text { Expected pattern } \\
\text { (slide) }\end{array}$ & $\begin{array}{l}\text { Observed pattern } \\
\text { (speech) }\end{array}$ \\
\hline $\begin{array}{l}\begin{array}{l}A \\
A\end{array} \text { B } \\
A\end{array}$ & 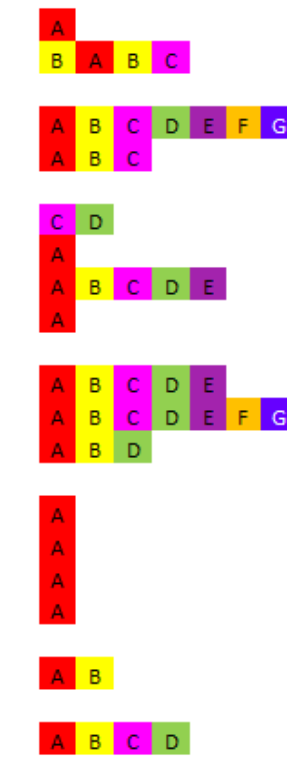 & 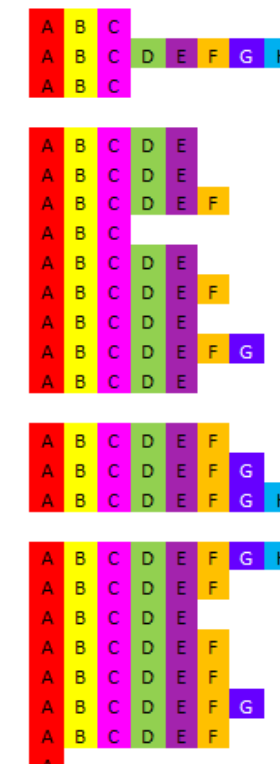 & 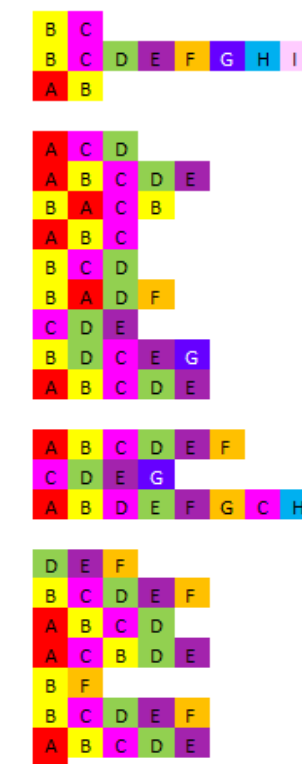 \\
\hline
\end{tabular}

Figure 3 represents the 'expected' and 'observed' patterns for the most consistently matching and least consistently matching lecturer.

\begin{tabular}{|l|l|l|l|}
\hline Jackson & Leaman \\
\hline $\begin{array}{l}\text { Expected pattern } \\
\text { (slide) }\end{array}$ & $\begin{array}{l}\text { Observed pattern } \\
\text { (speech) }\end{array}$ & $\begin{array}{l}\text { Expected pattern } \\
\text { (slide) }\end{array}$ & $\begin{array}{l}\text { Observed pattern } \\
\text { (speech) }\end{array}$ \\
\hline
\end{tabular}




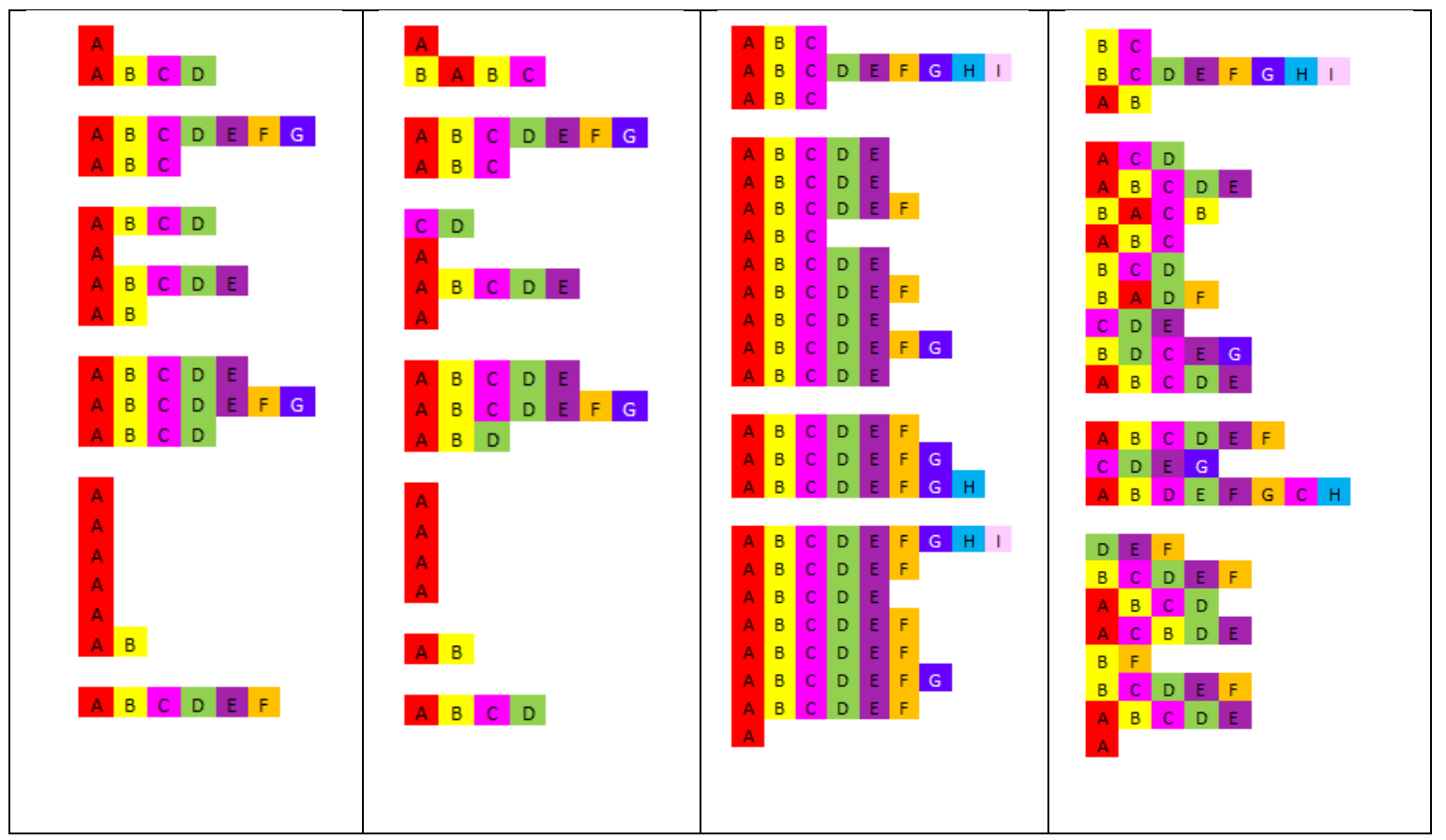

Figure 3: Visualisations of the extent of matching between speech and slide-text of the most and least consistently matching lecturers

The strings of letters representing the expected and observed patterns were converted to a statistic, here referred to as an 'integration score', which expressed whether and how closely a lecturer matched or did not match the pattern of their slides with their speech. Note that in referring to 'matching' or 'not matching' the slide's pattern, there is no implication that these results directly support judgements as to the pedagogical value of matching.

\section{Scoring speech-slide integration}

A statistical model was employed to represent the extent to which the observed pattern of integration matched or deviated from the expected pattern. The strings of letters were compared using a string-matching or edit-distance algorithm, such as those designed for spell-checking or text-matching, and which can easily be adapted for different purposes such as for measuring errors on text entry tasks (Soukoreff and MacKenzie, 2001).

The Levenshtein string distance statistic measures the 'minimal number of insertions, deletions and substitutions to make two strings equal' (Navarro, 2001: , p. 37) where all 'operations', or differences between strings (for example, the word 'Levenshtein' vs the word 
'Lvenshfeins'), gain a score of ' 1 ' (in the example: the deleted ' $\mathrm{e}$ ', the substitution of the ' $\mathrm{t}$ ' with ' $\mathrm{f}$ ' and the insertion of an ' $\mathrm{s}$ ' implies a score of ' 3 '). The higher the score, the more changes would need to be made to one string to make it match the other. Although there would be no insertions, as the analysis only focussed on what existing text-elements were integrated rather than examining addition of material, it was useful to be able to measure together 'deletions' (where a lecturer missed out a text-element in their speech) and 'substitutions' (addressing text-elements out of order).

The slide provided the 'expected' string of letters against which the 'observed' string of the lecturer's speech integration was compared. These two strings were processed in a spreadsheet containing a Macro for the Levenshtein edit distance algorithm: each slide was thereby given a Levenshtein distance score for comparison. For example, comparing the strings in Examples 1 and 2 in Table 3 below, there is a greater difference between the expected and observed strings in 1 than in 2 . In 1 , the string was not repeated at all, meaning the Levenshtein distance equals the length of the string (10). On the other hand, in 2, there is only one letter missing from the observed string, meaning the distance between the two strings is ' 1 '.

Table 3: Example of comparison of scaled Levenshtein string distances

\begin{tabular}{|c|l|l|l|l|l|}
\hline Example No. & $\begin{array}{l}\text { Expected } \\
\text { string }\end{array}$ & $\begin{array}{l}\text { Observed } \\
\text { string }\end{array}$ & $\begin{array}{l}\text { Levenshtein } \\
\text { Distance }\end{array}$ & $\begin{array}{l}\text { Scaled } \\
\text { Levenshtein } \\
\text { Distance }\end{array}$ & $\begin{array}{l}\text { Similarity } \\
\text { score }\end{array}$ \\
\hline 1 & ABCDEFGHIJ & & 10 & 1 & 0.50 \\
\hline 2 & ABCD & ABC & 1 & 0.25 & 0.80 \\
\hline 3 & A & & 1 & 1 & 0.50 \\
\hline
\end{tabular}

This score alone does not take into account the respective length of the strings; there will be a greater difference if one item is deleted from a short sequence than from a long sequence (Ainsworth et al., 2002). To account for length, Levenshtein distance scores were 
scaled (divided) by the length of the expected string sequence (in Examples 1 and 2: 10 and 4 respectively) to allow comparisons for the patterns on a 0-1 scale. In order to provide a more meaningful statistic this 'similarity' measure, which accounts for string length, was subjected to a reordering of the scores to provide a 0 -to- 1 scale, where ' 1 ' represents an exact match and ' 0 ' represents infinite difference. This was achieved by adding 1 to the scaled Levenshtein score, and then dividing 1 by this sum. The formula for the similarity measure is as follows:

$$
\text { Similarity }=1 /(1+\text { dist }) \text {. }
$$

It should be noted that absolute zero is impossible here, as to receive zero, the scaled Levenshtein distance needs to be above 1 . This score is only achievable if there are different letters added to the observed string: for example, adding KLMN to Example 2 above. This would not represent integration of the existing slide-text; rather it would represent the addition of slide-text in the speech. This is impossible in the present case, because although a lecturer can add speech that is not related to the slide-text, such as explaining, introducing or tangential speech, there is no associated slide-text to reference.

The lowest similarity score received for any of the slides was 0.33 , and the highest was 1 . Mean scores were calculated for all the slides for each lecture to give an integration score as displayed in ascending order in Table 4 below. It was considered that the closer to 1 the mean, the more systematic the lecturer was in their integration.

Table 4: Integration scores for each lecturer

\begin{tabular}{|l|c|c|}
\hline \multicolumn{1}{|c|}{ Lecturer pseudonym } & Integration score & $\begin{array}{c}\text { Std. Dev. (of mean } \\
\text { similarity score) }\end{array}$ \\
\hline Leaman & 0.69 & 0.16 \\
\hline Wright & 0.71 & 0.13 \\
\hline Vickers & 0.71 & 0.15 \\
\hline Cooper & 0.72 & 0.13 \\
\hline Kemp & 0.76 & 0.14 \\
\hline
\end{tabular}




\begin{tabular}{|l|l|l|}
\hline Underwood & 0.78 & 0.21 \\
\hline Horsley & 0.79 & 0.14 \\
\hline Ealy & 0.80 & 0.15 \\
\hline Moss & 0.80 & 0.20 \\
\hline Lake & 0.86 & 0.18 \\
\hline Jackson & 0.89 & 0.17 \\
\hline
\end{tabular}

A one-way Analysis of Variance test (ANOVA) (e.g. Lazaraton, 2002) was applied to the similarity scores for each slide of each lecture to test for differences between the lecturers in the extent to which their observed patterns matched their expected patterns, using the individual slides as the population and lecturer as the factor. Lecturers differed significantly from each other in the similarity of the pattern of speech to the slide-text: $F(10,364)=3.801$, $\mathrm{p}=<0.001$

\section{Considering the lecturer's relationship with the slide}

The next analytical step was to describe qualitative differences in slide-lecture practice. Schnettler (2006) identified two activities by which a presentation can be orchestrated: 'translating' (deciphering the slide-text) and 'conducting attention' (directing attention to particular elements). It was noted during the analysis of integrations that there were other practices not covered by these two categories: the lecturer contradicting the slidetext, or highlighting why it was important. In order to consider whether the speech might reveal anything about the lecturers' relationship with their slides, a qualitative DA approach was taken. This involved analysing examples of integration and the speech surrounding integrations, focussing on what the lecturer appeared to be doing with their integration of text.

\section{Caricatures of the slide-lecture}

The analysis focussed on the actions that the speech performed in relation to the slidetext, using Schnettler's (2006) activities as a starting point, thus the extent to which the 
speech 'translated' or 'conducted attention' was identified. This analysis was also intended to uncover any further activities which were carried out by the speech in relation to the slide-

text. The highest and lowest scoring lecturers were treated as the two extremes of approaches to slide integration. Here we considered the two lecturers who were quantitatively different in their approach to integration, to consider what the qualitative differences between them might be.

\section{Jackson had the highest integration score: he integrated his slide-text most}

consistently. This consistency might imply that his approach was closest to the 'reading off the slide' practice, or to Schnettler's (2006) 'performer' approach. Indeed on closer inspection, this was often the case, for instance the below slide (Figure 4) shows very close matches between the speech and slide-text. This is particularly evident in his integration of element $\mathrm{E}, \mathrm{F}$ and $\mathrm{G}$.

\begin{tabular}{|c|c|c|c|}
\hline $\begin{array}{l}\text { Expected } \\
\text { pattern }\end{array}$ & Slide-text & $\begin{array}{l}\text { Observed } \\
\text { pattern }\end{array}$ & Speech \\
\hline $\begin{array}{l}\mathrm{E} \\
\mathrm{F}\end{array}$ & $\begin{array}{l}\text { Bowlby (1969-1980) 'Child care and the growth of love' } \\
\text { Major influences: } \\
\text { Psychoanalysis } \\
\text { Ethology } \\
\text { Young child is 'biologically biased' to develop } \\
\text { attachments to its caregivers given its genetic endowment. } \\
\text { Biological function of attachment is protection of the } \\
\text { young } \\
\text { Psychological function of attachment is to provide security }\end{array}$ & $\begin{array}{r}\text { A } \\
\text { None } \\
\text { B } \\
\text { None } \\
\text { C } \\
\text { D } \\
\text { E } \\
\text { E None } \\
\text { None }\end{array}$ & $\begin{array}{l}\text {...Now John Bowlby came along and he wrote this book, } \\
\text { which at the time caused a lot of controversy, } \\
\text { at that time because it was saying: hold on a minute, there could } \\
\text { be a real problem here with mothers going to work. And the } \\
\text { problem is to do with this business of attachment. So he caused } \\
\text { a lot of trouble and he wasn't very popular. But it was a very } \\
\text { controversial book at that time. } \\
\text { His major influences on this, } \\
\text { on his writing, which really, he was really the first person in } \\
\text { psychology, apart from Freud of course much earlier, to really } \\
\text { begin to pull out the significance of this relationship and he did } \\
\text { for two reasons, } \\
\text { one a lot of his ideas came from psychoanalysis, } \\
\text { but also from another branch of the natural sciences called } \\
\text { ethology. } \\
\text { And OK, here's some fairly obvious basic ideas about it, a } \\
\text { young child is biologically biased to develop attachment to } \\
\text { its caregivers given its genetic endowment. } \\
\text { Now we noticed last week when I was talking about infancy, the } \\
\text { curious business about imitation which looks as if maybe it just } \\
\text { has to be something that's built in, and now we've got } \\
\text { something else, well, hold on a minute, } \\
\text { biologically biased to develop attachments to its caregivers, } \\
\text { well, in an obvious way it might make sense, but teasing apart } \\
\text { actually }\end{array}$ \\
\hline
\end{tabular}




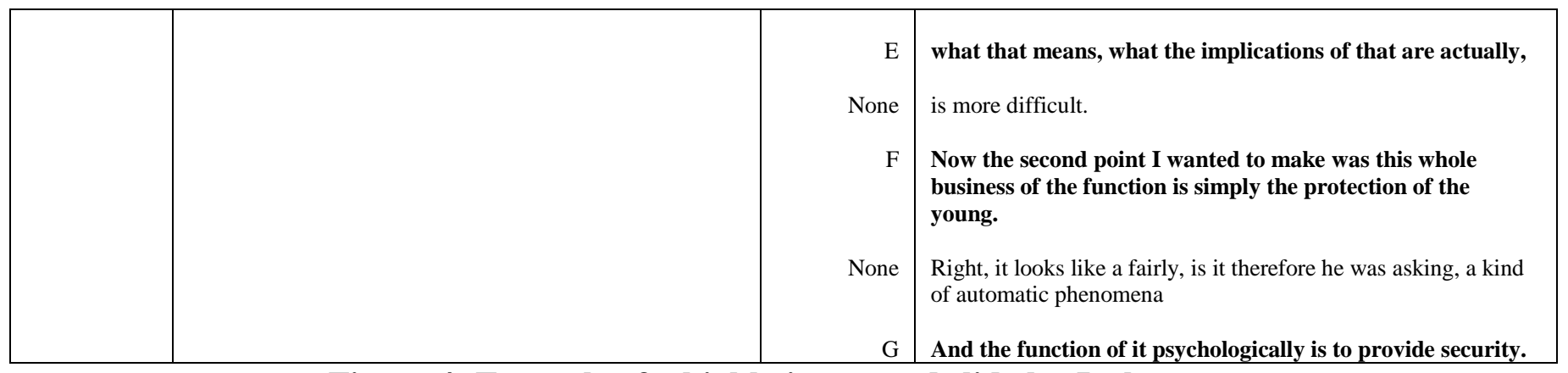

Figure 4: Example of a highly integrated slide by Jackson

It appears that the elements are being spoken about, rather than that the text is

somehow being performed. For instance where the speech first integrates slide-element E, the lecturer says 'and here's some fairly obvious basic facts about it', which provides a context for the following speech; he will be reading out these obvious and basic facts. Such an act might be considered to be conducting attention to the slide-element, using a directive to identify that the text will be integrated. Yet he wanted to do so in order to classify the information as being 'obvious' and 'basic'. However, once the slide-text is read out, or verbalised, he follows it by questioning the text using information previously learned. He says 'now we've got something else, well hold on a minute' before verbalising the slide-text again, which suggests to the audience that what is written on the slide is questionable in some way. He follows this with suggesting that if we attempt to pick it apart it is rather difficult. The lecturer is almost disagreeing with the slide-text, or else pointing out that although such a point has been made, it does not necessarily mean that it is a simple fact to be digested. Rather, students should be considering it in light of what they learned in the last lecture.

Jackson includes some extent of translation into the speech, i.e. in explaining the text or otherwise deciphering it for the audience. For instance, where he integrates element $\mathrm{C}$, he follows with a translation- 'so, you know...' Mostly the lecturer seems to signal that the text is self-explanatory, and as such he is not using the text-element as an object which needs to be explained to students. Rather his relationship with the slide appears to be based on his indicating or referring to specific elements in order to assess them. There were many further 
examples of this lecturer talking about the slide-text in such a way. For example, the quote below (instances of integration are in bold):

“Here's some features of it I think are worth just reminding you about. Attachments are not just to anyone. Now we notice that, he's saying that but remember at the very beginning you get this social responsiveness for the first couple of months, but that's not attachment. They are selective, focused on specific individuals who elicit attachment behaviour in a manner, form and extent that is not found in the child's interactions with other people. I know what it means because my mother can still really get to me, ha-ha I shouldn't admit that should I?

Attachments provide comfort and security, the outcomes of being close to the attachment object. That's fair enough."

Before reading out the list of features that appear on the slide the lecturer notes that he thinks these features are important to remember. In this way the lecturer might be signalling the importance of the slide-text to the general thesis of the lecture. The lecturer follows the reading of the first item on the list by linking back to what was previously learned to help explain or translate the statement; that responsiveness in attachment is more than just general social responsiveness. It is noted that later the lecturer agrees with the text-' that's fair enough'.

Although this lecturer most consistently addresses his slide-text, he does so predominantly to question or provide an assessment of it. The lecturer does not use his slidetext as a script to tell him what to talk about, but instead uses it as an artefact of reference. This 'referring' style is particularly salient when compared against the practices of the lowest 
integration scoring lecturer; Leaman, who did not regularly assess the slide-text. Instead, the slide-text is more subtly woven into her speech. An illustration of this is provided in Figure 5. Here, if the speech were read alone, it might be impossible to tell that there was text on the slide at the time.

\begin{tabular}{|c|c|c|c|}
\hline $\begin{array}{l}\text { Expected } \\
\text { pattern }\end{array}$ & Slide & $\begin{array}{l}\text { Observed } \\
\text { pattern }\end{array}$ & Speech \\
\hline A & $\begin{array}{l}\text { JOHN BOWLBY } \\
\text { Predisposition to maintain proximity to caregiver, } \\
\text { and behave in ways that attract their attention and } \\
\text { engage their involvement - safe haven } \\
\text { Also predisposition to explore the world around } \\
\text { them - use caregiver as a safe base }\end{array}$ & $\begin{array}{r}\text { A } \\
\text { None } \\
\text { B } \\
\text { None } \\
\text { B } \\
\text { None }\end{array}$ & $\begin{array}{l}\text { Bowlby } \\
\text { suggested that young people have } \\
\text { a predisposition to maintain proximity to a } \\
\text { caregiver, and this is the heart of attachment this is } \\
\text { what attachment is about, it's about maintaining } \\
\text { proximity. } \\
\text { It's about staying close to somebody who's going to } \\
\text { look after you because of course: infancy is a very } \\
\text { dangerous experience. If you're helpless you can't feed } \\
\text { yourself, you can't clothe yourself, you need someone } \\
\text { else to look after you. } \\
\text { You have to elicit care from somebody else } \\
\text { if you can't do it yourself. So this is what attachment is } \\
\text { all about. And it's what attachment is all about all the } \\
\text { way through life as well. So this idea about felt } \\
\text { security, } \\
\text { about keeping somebody close, that's what } \\
\text { attachment is about. } \\
\text { And Bowlby talked about safe haven behaviours } \\
\text { and safe base, secure base behaviours. So safe haven } \\
\text { behaviours are this predisposition to maintain } \\
\text { proximity to the caregiver, behaviours that attract } \\
\text { the attention of the caregiver, and engage their } \\
\text { involvement... }\end{array}$ \\
\hline
\end{tabular}

Figure 5: Example of slide by Leaman

The boundaries between slide-text-elements in the speech are less marked, as evidenced by the first speech-sentence. Element A is merged together with B in the same speech-sentence. This merging is also evident in her integration of elements B and C. Here, she skips the majority of the text to merge the two phrases written in italics on the slide: 'Safe haven' and 'Safe base', before going on to define or translate these phases separately afterwards- 'so safe haven behaviours are...' Here the lecturer is speaking the concept before explaining it, such that the students need not see the concepts on the slide. What is more evident here is the extent of translation of the slide-text being carried out, as much of the slide-text is explained in other terms without explicitly referring to it. Also, the lecturer 
appears to make more of an effort to combine the speech and text into a single story, compared to Jackson's approach which served to separate them. This is clear in the quote below in which the lecturer more subtly integrates the words appearing on the screen (slidetext integrations shown in bold).

"Now when we talk about attachment, often people know what we mean when we talk about parent-child attachments or child-parent attachments. And most of this work is based on how the infant expresses emotion and how the caregiver responds to that emotion. So what we need to think about is when we're looking at parental and child interactions and we're looking at this dyad interacting together, how do we conceptualise what the attachment is? This bond between parents and their children, how do we conceptualise it"

The slide-text is woven into the lecturer's sentence, serving to convert the text from solitary phrases to a more articulate narrative. The lecturer adds some information to the narrative as an extended translation. Overall, this lecturer seems to be using the slide-text as some form of flexible scaffold for the lecture, in which the text is not assessed, rather it becomes a part of the speech. Further, the role of the speech as a translator of the slide-text is more obvious.

Functions of the speech-slide-text relationship

Through considering the practices of both the most and the least integrative lecturers, it is proposed that there are two functions of the speech-slide-text relationship in slidelectures;

1) the 'referent' function, characterised by the lecturer providing an assessment on the slide-text, and; 
2) the 'scaffolding' function characterised by the lecturer's speech blending and translating the slide-text within the spoken narrative.

The described analysis was carried out on the remainder of the slides for each of the two lecturers to consider the extent to which the lecturers display characteristics of one kind of relationship over another. The speech acts were separated into the two relationships that they appear to indicate, and instances in which they occurred were recorded throughout the whole lecture transcript. Here 'conducting attention', 'questioning', 'agreeing/ disagreeing' and 'signalling importance' were considered as acts which are used when a lecturer refers to his slide-elements, as they serve to separate speech from slide as two distinct aspects of the presentation. Verbalising also fits here, as it was considered that in verbalising the text the lecturer draws attention to the text on the slide, and again highlights the distinctness of speech and slide. 'Merging', 'translating' and 'combining' are considered to be aligned with the 'scaffolding' relationship, as these serve to combine the speech and slide information into a single message: the speech and slide-text are not identified as distinct messages. This analysis is detailed in Table 5 below.

\section{Table 5 Quantifying the extent of the 'referent' and 'scaffolding' relationships}

A $\chi^{2}$ analysis was carried out to compare the total number of speech acts within each relationship type that the lecturers produced. The difference in relationship indicators between lecturers was significant: $\chi^{2}(\mathrm{df}: 1, \mathrm{~N}=291)=63.08, p<0.001$. It was concluded that the lecturers differed significantly in the relationship indicators that they employed in their lectures.

\section{Reliability of the indicators}

The indicators were checked for reliability by employing a colleague who was given two slide examples from each of the two lecturers (approximately $10 \%$ of total number of slides), along with descriptions of the speech acts. The coder was asked to identify whether 
the speech acts were present in the examples and how frequently they occurred. This was then compared against the same coding performed by the authors. It should be noted that the second coder was given the entire slide-speech transcript for the slides, yet the examples above are clipped.

The interrater-reliability, using the Kappa statistic to determine consistency amongst the two coders, was found to be in substantial agreement: Kappa $=0.846(p<0.001)$. There was high agreement that the same speech acts were being carried out for the four slides above.

\section{Discussion}

This study quantified and described lecturers' differing relationships with their slides. Simply looking at the 'observed' patterns side-by-side in Figure 3 gives an idea of the difference in approach to integration between two lecturers. Moreover, this inconsistency of approach varies across a considerable range - from the most consistent and systematic lecturer Jackson who received an integration score of 0.89 to Leaman who received an integration score of 0.69 indicating significantly differing levels of deviation from the slide pattern with their speech. However, in the way in which lecturers integrated text was also characteristically different.

It was identified that there are two relationship styles that were employed by the highest and lowest scoring lecturers in terms of integration: 'referent;' and 'scaffolding'. Here slide-text is treated as either an object to comment on or is blended into the speech. Jackson employed indicators of a 'referent' relationship in $70.45 \%$ instances of integration throughout the lecture, whereas Leaman employed them in $21.67 \%$ of instances of integration. On the other hand, Jackson employed indicators of a 'scaffolding' relationship in $29.55 \%$ of instances of integration, compared to Leaman who employed them in $78.33 \%$ of 
instances of integration. It may be suggested then that a lecturer who employs a referent relationship might be more concerned with systematically addressing each element on the slide in the expected order, whereas the lecturer employing a scaffolding relationship might be less concerned with such following of the slide-text.

It must be noted that although the two lecturers showed significant preferences for different approaches, the lecturers did not consistently display characteristics of only one relationship. Thus the function of slide-text might vary both between and within slidelectures, and might depend heavily on how the lecturer intends to use each text-element. As a consequence, the lecturers' relationship with their slides is not immediately evident and as such these relationships need further empirical examination for their relative impacts on the learning environment.

The proposed 'referent' and 'scaffolding' relationships appear to be reflected in literature commenting on PowerPoint practice, yet it seems that most often it is the 'scaffolding' relationship described. For instance Adams' (2006) identifies the role of slides as being where the lecture resides: the information contained is elaborated by the lecturer through their verbal exposition. Further Maxwell's (2007) critical account of the prevailing role of PowerPoint is that it provides a summary for the lecture, which is repeated by the lecturer's speech. Yet as our analysis has identified, this predictable level of integration is not always the case within the 'scaffolding' relationship, and often the integration is much more intricate.

In terms of the 'referent' relationship, there is comparatively less commentary on its use. Rather, the literature which discusses this kind of relationship often calls for more lecturers to adopt it over the scaffolding relationship, suggesting that it is a less common strategy. For example Maxwell argues for the role of the slideshow as an artefact to be 
commented and elaborated upon (Maxwell, 2007). Others focus on the adoption of multimedia design principles; a succinct headline, along with visual evidence for that headline (Alley and Neeley, 2005; Nagmoti, 2017; Johnson and Christensen, 2011). Pate and Posey's (2016) experiments revealed that slides designed following multimedia principles (i.e. images with labels) contributed to superior performance and satisfaction of students more than traditional text-based slides. Here, the lecturer shows visual evidence for their arguments, rather than text summaries of their lecture. It must be noted that the suggested lecturing model in these and similar studies (e.g. de Koning et al., 2017; Ari et al., 2014; Schüler et al., 2013) calls for much reduced levels of slide-text compared to the slides examined in the current study.

Although the data were collected during the 2009/10 academic year, it is highly likely that the results are applicable to lectures today owing to the significant 'constraining qualities' of PowerPoint/slideware (Kernbach et al., 2015) which potentially force lecturers into the kinds of relationships discussed here. The constraining qualities that Kernbach et al. (2015) 'bulleting', 'sequencing', 'monotonous ritualizing', 'reading slide text aloud' speak of similar concepts to the relationship indicators employed in this paper. Although lecture practices are gradually shifting towards more active teaching methods, for example the flipped classroom (e.g. Bergmann and Sams, 2012) or 'active lectures' (e.g. Pickering and Roberts, 2018) which may make less use of the slide-lecture format, slide-lecture components are still a predominant feature of instructional messages which may accompany these approaches. Students may be asked to watch recorded slide-lectures online within the flipped classroom approach. As Kernbach et al.'s constraining qualities are embedded into the software, it is likely that a lecturer's integration approach will be driven to one of the relationships whenever there is text on screen, even if the text/lecture is significantly reduced. 
There are many integration options open to lecturers when conducting slide-text in lectures and their choices for integration might depend on personal preferences, familiarity with the subject, attitudes and beliefs regarding lecture pedagogy. Furthermore, their academic discipline might carry its own idiosyncrasies regarding the kinds of information displayed on their PowerPoint screens (Garrett, 2016) which might influence the ways in which slide-text is spoken about. Indeed, the cultural studies lectures discussed by Zhao and van Leeuwen (2014) appear to adopt the 'referent' approach as standard. Cultural studies, as described by Zhao and van Leeuwen, is a discipline in which students are invited to engage with the ideas presented, using images and other modalities as trigger for a personally meaningful experience, compared to the 'lecturer-explaining-concepts' model typical of psychology lectures. This is reflected in the proportion of Zhao and van Leeuwen's seven lecture's worth of slides which were image based rather than text based (of 268 slides, only $24.25 \%$ were exclusively text based, in this paper $91.57 \%$ of slide-elements were textual). It is important to note that slides are conceptualised by Zhao and van Leeuwen as semiotic resources which enable knowledge to be recontextualised in the classroom. In other words, in cultural studies classrooms slides do not just convey information, they transform meanings. This practice is more suggestive of our 'referent' relationship.

\section{Conclusions}

Whichever relationship the lecturer has with their slide-text, it should be acknowledged that live slide-lectures represent an unpredictable sub-type of multimedia instruction. This unpredictability might result in a potentially fraught situation when the speech and slide are not integrated as expected, i.e. what the lecturer is saying is not related to the expected text-element on screen. Rowley-Jolivet (2002) describes the audience's task during a slide-presentation as a difficult one when characterised within Mayer et al's notions of dual processing and cognitive load (e.g. Mayer, 2005; Mayer and Moreno, 1998; Mayer et 
al., 1999; Mayer and Moreno, 2003). Rowley-Jolivet suggests that the speaker must follow, or 'synchronise' their verbal commentary with the slides, whilst the audience must negotiate both the slide content and the synchronisation of it by detecting and processing the 'linear progression and semiotic mix imposed by the speaker' (, p. 21). Applied to a slide-lecture, the student expects the lecturer to systematically address the slide-text. Those who expect that the lecturer will do so in order to expand on the slide text could easily be confused by a lecturer who uses the 'referent' approach. Similarly, those who are seeking an appraisal of the information on screen might be frustrated by a 'scaffolding' approach. Lecturers who are consistent with their integration of slide-text might go some way towards making slidelectures easier to follow. Yet it remains unclear which kind of relationship (referent vs scaffolding) is better for learning. Either way, it seems that copious amounts of slide-text might be problematic.

We suggest that further research should examine how learning might be influenced by different types of speech-slide relationship by, for example, examining student reflections on the different relationships. It would be useful to examine how student attention can be optimally managed in a slide-lecture, and whether particular integration practices can facilitate this management. An investigation into the extent to which lecturers employ the slide-lecture approach for entire sessions or as part of a range of approaches during a session would provide useful insights into how much of lecture time a student is employed in attempts to synchronise speech and slide-text. Arguably, there is a need for some consensus, discipline or guidance in relation to the practices of coordinating speech and slide-text.

\section{Acknowledgements}

Thank you to Dr. Matthew Inglis of Loughborogh University for assisting with the selection and application of the Levensthein statistic and similarity score. 


\section{Declaration of interest statement}

No potential conflict of interest was reported by the authors.

\section{Funding}

This work was supported by the Economic and Social Research Council (ESRC).

Madeline J. Hallewell, $\mathrm{PhD}$, is currently a Research Fellow in Human Factors at the University of Nottingham, where she also completed her PhD in Education in 2013. She has a background in teaching in UK secondary, further and tertiary education contexts where she has taught social science topics. She is a mixed-methods researcher, and her research interests centre on how humans interact with their environments, and how this interaction can affect their learning, wellbeing and performance. She is particularly interested in social semiotics and reactions to multimedia learning and multimodal environments. Her most recent research produced user requirements for and evaluations of digital games to teach hearing aid users about the advanced functionalities of their hearing aid. Future work will involve the development of dynamic lighting systems for crowd control and the reduction of trespass and suicides in train stations and level crossings.

Charles Crook is a Professor of ICT and Education. He is a member of the Learning Sciences Research Institute at Nottingham and is a developmental psychologist by background. After research at Cambridge, Brown and Strathclyde universities, he lectured in Psychology at Durham University and was Reader in Psychology at Loughborough University. Much of this work involves new technology. He was a founder member of the European Society for Developmental Psychology and was long-time editor of the Journal of Computer Assisted Learning.

\section{References}

Adams C. (2006) PowerPoint, habits of mind, and classroom culture. Journal of Curriculum Studies 38: 389-411.

Ainsworth S. (2006) DeFT: A conceptual framework for considering learning with multiple representations. Learning and Instruction 16: 183-198.

Ainsworth S, Clarke D and Gaizauskas R. (2002) Using edit distance algorithms to compare alternative approaches to ITS authoring. Intelligent Tutoring Systems. Springer, 873882.

Alley M and Neeley KA. (2005) Rethinking the design of presentation slides: A case for sentence headlines and visual evidence. Technical communication 52: 417-426.

Ari F, Flores R, Inan FA, et al. (2014) The effects of verbally redundant information on student learning: An instance of reverse redundancy. Computers \& Education 76: 199-204.

Bergmann J and Sams A. (2012) Flip your classroom: Reach every student in every class every day, USA: International society for technology in education.

Bucher H-J and Niemann P. (2012) Visualizing science: the reception of powerpoint presentations. Visual Communication 11: 283-306.

Coulthard M. (2014) An introduction to discourse analysis, Oxon: Routledge. 
de Koning BB, van Hooijdonk CMJ and Lagerwerf L. (2017) Verbal redundancy in a procedural animation: On-screen labels improve retention but not behavioral performance. Computers \& Education 107: 45-53.

Gabriel Y. (2008) Against the tyranny of PowerPoint: Technology-in-use and technology abuse. Organization Studies 29: 255.

Garrett N. (2016) How Do Academic Disciplines Use PowerPoint? Innovative Higher Education 41: 365-380.

Gourlay L. (2012) Cyborg ontologies and the lecturer's voice: a posthuman reading of the 'face-to-face'. Learning, Media and technology 37: 198-211.

Hallewell MJ and Lackovic N. (2017) Do pictures 'tell'a thousand words in lectures? How lecturers vocalise photographs in their presentations. Higher Education Research \& Development: $1-15$.

Jewitt C. (2009) The Routledge handbook of multimodal analysis, London: Routledge.

Johnson DA and Christensen J. (2011) A comparison of simplified-visually rich and traditional presentation styles. Teaching of Psychology 38: 293-297.

Kernbach S, Bresciani S and Eppler MJ. (2015) Slip-sliding-away: A review of the literature on the constraining qualities of PowerPoint. Business and Professional Communication Quarterly 78: 292-313.

Kinchin IM, Chadha D and Kokotailo P. (2008) Using PowerPoint as a lens to focus on linearity in teaching. Journal of Further and higher Education 32: 333-346.

Knight M. (2015) The Ubiquitousness of PowerPoint. Business and Professional Communication Quarterly 78: 271-272.

Knoblauch H. (2008) The performance of knowledge: Pointing and knowledge in Powerpoint presentations. Cultural sociology 2: 75-97.

Lazaraton A. (2002) Quantitative and qualitative approaches to discourse analysis. Annual Review of Applied Linguistics 22: 32.

Mann S and Robinson A. (2009) Boredom in the lecture theatre: An investigation into the contributors, moderators and outcomes of boredom amongst university students. British Educational Research Journal 35: 243-258.

Maxwell A. (2007) Ban the bullet-point! Content-based PowerPoint for historians. The History Teacher 41: 39-54.

Mayer R, E. (2001) Multi Media Learning, Cambridge: Cambridge University Press.

Mayer R, E. (2005) The Cambridge Handbook of Multimedia Learning, New York: Cambridge University Press.

Mayer R, E and Moreno R. (1998) A Split-Attention Effect in Multimedia Learning: Evidence for Dual Processing Systems in Working Memory. Journal of Educational Psychology 90: 312-320.

Mayer R, E, Moreno R, Boire M, et al. (1999) Maximizing Constructivist Learning from Multimedia Communications by Minimizing Cognitive Load. Journal of Educational Psychology 91: 638-643.

Mayer RE and Moreno R. (2003) Nine Ways to Reduce Cognitive Load in Multimedia Learning. Educational Psychologist 38: 43 - 52.

Nagmoti J. (2017) Departing from PowerPoint default mode: Applying Mayer\&\#39;s multimedia principles for enhanced learning of parasitology. Indian Journal of Medical Microbiology 35: 199-203.

Navarro G. (2001) A guided tour to approximate string matching. ACM computing surveys (CSUR) 33: 31-88.

Nowak MK, Speakman E and Sayers P. (2016) Evaluating PowerPoint Presentations: A Retrospective Study Examining Educational Barriers and Strategies. Nursing Education Perspectives 37: 28-31. 
Pate A and Posey S. (2016) Effects of applying multimedia design principles in PowerPoint lecture redesign. Currents in Pharmacy Teaching and Learning 8: 235-239.

Pickering JD and Roberts DJH. (2018) Flipped classroom or an active lecture? Clinical Anatomy 31: 118-121.

Pozzer-Ardenghi L. (2007) " Look at what I am saying": multimodal science teaching. Dept. of Curriculum and Instruction. British Columbia: University of Victoria.

Rowley-Jolivet E. (2002) Visual discourse in scientific conference papers A genre-based study. English for specific purposes 21: 19-40.

Schnettler B. (2006) Orchestrating bullet lists and commentaries. A video performance analysis of computer supported presentations. In: H K (ed) Video Analysis: Methodology and Methods. Qualitative Audiovisual Data Analysis in Sociology. Frankfurt am Main and New York: Lang, 155-168.

Schüler A, Scheiter K and Gerjets P. (2013) Is spoken text always better? Investigating the modality and redundancy effect with longer text presentation. Computers in Human Behavior 29: 1590-1601.

Smith- Shank D, L. (2010) Semiotic pedagogy and visual culture curriculum, Rotterdam, the Netherlands: Sense Publishers.

Soukoreff RW and MacKenzie IS. (2001) Measuring errors in text entry tasks: an application of the Levenshtein string distance statistic. CHI '01 Extended Abstracts on Human Factors in Computing Systems. Seattle, Washington: ACM, 319-320.

Young JR. (2004) When good technology means bad teaching: Giving professors gadgets without training can do more harm than good in the classroom, students say. The Chronicle of Higher Education 51: 12.

Zhao S and van Leeuwen T. (2014) Understanding semiotic technology in university classrooms: a social semiotic approach to PowerPoint-assisted cultural studies lectures. Classroom Discourse 5: 71-90. 
Word count (including figures): 8267 